\title{
A gastronomia e o turismo: Um estudo na fronteira Jaguarão/BR e Rio Branco/UY
}

\author{
La gastronomía y el turismo: Un estudio en la frontera Jaguarão/BR e Río
} Branco/UY

The gastronomy and tourism: A study on the border Jaguarão / BR and Rio Branco / UY

\author{
Tecg. Gildo Janke ${ }^{1}$ \\ Tecg. Diego Pautz Palmieri² \\ Marysol Fernandez Garcia Janke J $^{3}$
}

\begin{abstract}
Resumo
A gastronomia é um potencial atrativo no turismo, uma vez que pode gerar experiências únicas e memoráveis. Ela faz parte da experiência turística, não se dissociando desta, e ainda se trabalhada como patrimônio cultural imaterial pode distinguir uma região, evidenciando suas peculiaridades e reforçando sua autenticidade. $\mathrm{O}$ patrimônio gastronômico, a fim de reforçar seus diferenciais para atrair os visitantes, pode ser evidenciado pelo desenvolvimento de roteiros turísticos, eventos, os quais a gastronomia é o foco de seus planejamentos. O presente trabalho visa analisar a gastronomia como parte do processo de interação cultural na Fronteira entre o Brasil e Uruguai, por meio das cidades de Jaguarão (BR) e Rio Branco (UY) e tem como finalidade realizar diagnóstico do potencial gastronômico e turístico brasileiro e uruguaio, na direção de elaborar proposições capazes de promover o desenvolvimento do segmento de turismo gastronômico, logo cultural no município de Jaguarão. Para o diagnóstico foram realizadas pesquisas bibliográficas e documentais, assim como pesquisa de campo, por meio de conversas informais com moradores locais, e análise dos cardápios dos estabelecimentos.
\end{abstract}

Palavras-Chave: Turismo; Gastronomia; Identidade Cultural; Fronteira.

\section{Resumen}

La gastronomía es un atractivo potencial en el turismo, ya que puede crear experiencias únicas y memorables. Es parte de la experiencia turística, no disociar este, y todavía trabajado como patrimonio cultural inmaterial puede distinguir una región, destacando sus peculiaridades y reforzar su autenticidad. El patrimonio gastronómico con el fin de fortalecer sus diferenciales para atraer a los visitantes, puede demostrar las vigas de itinerarios turísticos, eventos, en que la cocina es el centro de su planificación. Este estudio tiene como objetivo analizar la comida como parte del proceso de interacción cultural en la frontera entre Brasil y Uruguay, a través de las ciudades de Jaguarão (BR) y Río Branco (UY) y tiene como objetivo realizar un diagnóstico del potencial gastronómico y turístico brasileño y uruguayo, en la dirección de la preparación de propuestas que promuevan el desarrollo del sector turismo gastronómico, pronto, cultural, en la ciudad de Jaguarão. Para el diagnóstico se llevaron a cabo la investigación bibliográfica y documental, así como la investigación de campo, a través de conversaciones informales con los residentes locales, y el análisis de los menús de los establecimientos.

\footnotetext{
${ }^{1}$ Tecnólogo em Gestão do Turismo; Universidade Federal do Pampa; Jaguarão, Rio Grande do Sul, Brasil; gjanke63@gmail.com.

${ }^{2}$ Tecnólogo em Gestão do Turismo, Universidade Federal do Pampa; Jaguarão, Rio Grande do Sul, Brasil; diegopautz560@gmail.com.

${ }^{3}$ Graduanda em Pedagogia, Universidade Federal do Pampa; Jaguarão, Rio Grande do Sul, Brasil; mfjanke@gmail.com.
} 
Palabras claves: Turismo, Gastronomía, Identidad Cultural, Frontera.

\begin{abstract}
Gastronomy is an attractive potential in tourism, since it can create unique and memorable experiences. It is part of the tourist experience, not dissociating this, and still worked as intangible cultural heritage can distinguish a region, highlighting its peculiarities and reinforcing its authenticity. The gastronomic heritage in order to strengthen its differentials to attract visitors, can be evidenced by the development of tourist itineraries, events, which cuisine is the focus of their planning. This study aims to analyze the food as part of the cultural interaction process on the border between Brazil and Uruguay, through the cities of Jaguarão (BR) and Rio Branco (UY) and aims to perform diagnosis of the Brazilian gastronomic and tourist potential and Uruguay, in the direction of preparing proposals that promote the development of gastronomic tourism sector, cultural soon in the city of Jaguarão. For the diagnosis were conducted bibliographic and documentary research, as well as field research, through informal conversations with local residents, and analysis of the menus of establishments.
\end{abstract}

Keywords: Tourism; Gastronomy; Cultural identity; Border

\title{
1. Introdução
}

O turismo é um setor dinâmico, que influencia a economia do país, auxilia no rompimento das barreiras, ajuda na comunicação e transmissão de experiências entre os povos e quando feito de forma responsável proporciona benefícios às pessoas e à região do destino turístico. Em se tratando de Brasil, no quesito cultura e pessoas com dom e criatividade para produzir cultura imaterial com características únicas e incríveis, o país é craque, porém ainda há poucos incentivos, apoio e condições adequadas de infraestrutura, para o país poder oferecer uma gama de variedades gastronômicas para seus públicos. Nesse contexto, a comunidade local se torna um importante aliado, não qual através dos pequenos produtores, faz com que se produzam peculiaridades e produtos regionais, fazendo com que a produção local se torne um fator de desenvolvimento do município. $\mathrm{O}$ fato de a matéria-prima vir da própria região faz com que a comida tenha características locais e únicas, por se tratar de técnicas culturalmente passadas de geração a geração. Assim, verificou-se que a fronteira possui potencial de atratividade turística nesse segmento, mas que precisa ser trabalhado mediante intervenção por parte do poder público, com apoio da comunidade local e da iniciativa privada. Diante disso o presente trabalho discorre sobre a importância do patrimônio cultural gastronômico atrelado ao turismo na cidade de Jaguarão (Brasil) e Rio Branco (Uruguai) sendo que neste local há uma diversidade de empreendimentos que servem comidas típicas da região. Percebe-se que é de grande valia para o turismo analisar os empreendimentos do lado brasileiro, identificando que através do saber tradicional se representa o patrimônio cultural, integrando e despertando memórias, tradições e o desenvolvimento social dos povos. 
A gastronomia enquanto cultura revela a identidade de um povo, de uma localidade, mostrando os costumes e tradições que dizem respeito ao modo de preparar os pratos com técnicas próprias e ingredientes específicos da região. Dessa forma, a cultura gastronômica pode ser um importante instrumento de expressão e valorização da identidade de uma comunidade, e se torna um atrativo para o turismo, fazendo com que seja aguçada a curiosidade do turista.

A região da Fronteira Sul é caracterizada por ter influencia da cultura portuguesa e espanhola que neste território lutavam por terras. A cultura onde se manifesta, ocorre à transformação de seus valores em objetos de lembranças e registros que repassam a identidade do lugar visitado, sendo assim, ressaltamos a importância da gastronomia como atrativo turístico-cultural, visto que ela não atende somente à necessidade humana de se alimentar, mas também age como instrumento de integração entre os povos através da socialização dos traços culturais específicos de cada comunidade.

Este artigo tem como objetivo geral inventariar algumas comidas típicas uruguaias ofertadas na fronteira enquanto atrativo turístico no município de Jaguarão. A fundamentação teórica está divida em três partes. Na primeira são apresentados os primeiros estudos em relação à fronteira e sua gastronomia típica. A segunda sessão trata da gastronomia como fator de produto turístico e sua ligação com a fronteira, evidenciando as vantagens de se ter uma rica culinária em um destino turístico. E, finalmente, na última parte, considerações finais, nas quais serão perspectivadas algumas possibilidades para o fomento da gastronomia local como potencial turístico para Jaguarão e a Fronteira com o Uruguai.

O método adotado para a realização do artigo inclui revisão bibliográfica, por meio de aportes teóricos sobre os assuntos pertinentes ao objeto de estudo, ou seja, definições de gastronomia, turismo, cultura e patrimônio cultural utilizando os seguintes autores: ÁVILA (2009), CHAGAS (2006), Cordeiro; Menegazzi (2013), JONES; JENKINS (2002), MASCARENHAS (2005), MARTINS (2010), PAIXÃO (2004 e 2006). Foram também realizadas consultas em sites de periódicos científicos, artigos, dissertações e teses, além de entrevistas informais com proprietários de estabelecimentos que oferecem pratos diferenciados da cultura Uruguaia na cidade de Jaguarão. Na pesquisa de campo, adotou-se o método quanti-qualitativo e objetivou-se coletar informações mais específicas acerca da oferta gastronômica dos empreendimentos da cidade de Jaguarão. A análise se deu através de cardápios de restaurantes e empreendimentos ligados à comercialização de produtos gastronômicos, constantes na folhetaria da secretaria de turismo, no período de Julho/2016 


\section{A cultura gastronômica na Fronteira Jaguarão/Brasil e Rio Branco/Uruguai: A oferta pelo lado brasileiro da comida uruguaia}

O presente trabalho visa à compreensão da gastronomia produzida na fronteira, como fator diferencial regional para a atração turística. Inserido na Região Sul do Rio Grande do Sul, pertencendo à região turística da Costa Doce, o município de Jaguarão destaca-se no turismo de compras, principalmente por sua localização dar-se na fronteira com a cidade vizinha de Rio Branco, no Uruguai. As cidades estão separadas somente pela ponte Internacional Mauá que faz a travessia sobre o rio Jaguarão, que deu origem ao nome da cidade. O Município possui de acordo com Instituto Brasileiro de Geografia e EstatísticaIBGE (2010) 27.931 habitantes, sendo que vale ressaltar que suas principais atividades econômicas são: agropecuária e pecuária, porém em alguns meses do ano, mais precisamente o mês de fevereiro a economia local é diretamente impactada com o turismo (CLICRBS, 2015), traves do evento de Carnaval. A cidade também, conhecida pelos seus prédios históricos, obteve em 2011 o tombamento de 650 prédios pelo Instituto Patrimônio Histórico e Artístico Nacional- IPHAN. Na gastronomia, o município possui um número aproximado de 20 estabelecimentos relacionados à alimentação identificados no Folder Turístico de Jaguarão (2013), na qual é importante destacar sua importância gastronômica, ou seja, os pratos típicos da culinária da fronteira ofertados nos empreendimentos do município.

No gráfico a seguir pode-se verificar a quantidade de empreendimentos do lado brasileiro que serve os pratos e que tipos de pratos segundo os dados levantados, na qual foram verificados 20 empreendimentos:

Gráfico 1: Número de empreendimentos

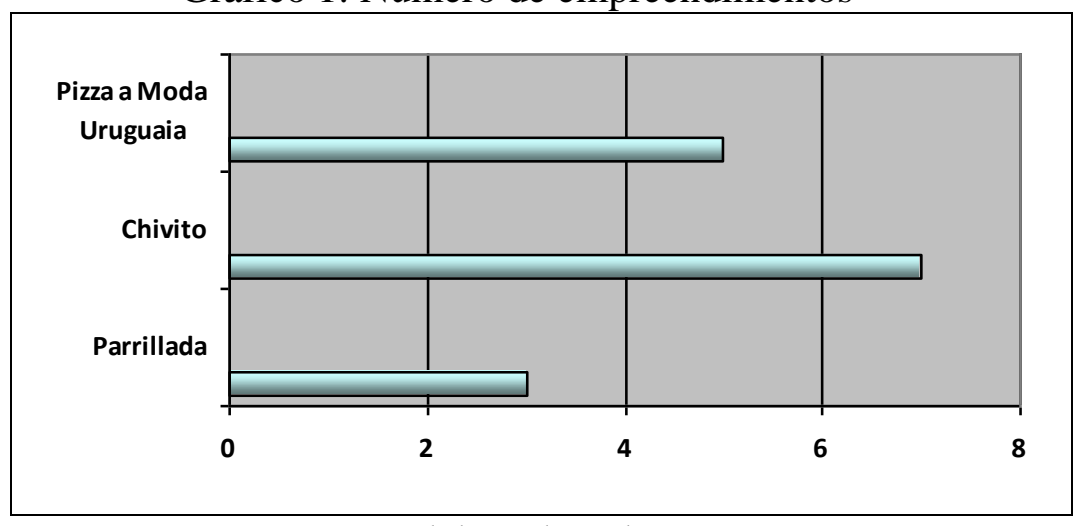

Fonte: Elaborado pelo autor 
No gráfico 1, colocamos a proporção do numero de empreendimentos que serve cada tipo de prato, na qual podemos destacar que: 5 (cinco) empreendimentos servem a pizza a moda uruguaia; 7 (sete) empreendimentos servem o chivito e por fim apenas 3 (três) fazem a parrillada.

A gastronomia enquanto cultura, desperta curiosidades nas pessoas e, como o turismo, é mediador para saciar as inúmeras curiosidades do turista, também, transmite a ideia de status e classe social não apenas para o turista como para a população, no qual o mesmo tem a curiosidade de provar o gosto da culinária, provar o sabor e vivenciar os costumes da comunidade em que visitou. A culinária na fronteira é tão viva que do lado brasileiro, se comercializa pratos típicos uruguaios, proporcionando o turista à experiência de degustar um alimento típico da região, sem precisar sair do Brasil.

Pode-se afirmar que a cultura de um povo não se exprime apenas nos aspectos físicos como os museus, monumentos, arquitetura, etc. ela está também nos saberes, no artesanato, nas músicas e danças típicas de uma região, na gastronomia, nas línguas, lendas, festas, enfim, no saber fazer que se denomine Patrimônio Cultural Imaterial, assim destacamos a importância da culinária típica da região para a comunidade da fronteira, com o reconhecimento do saber sobre o seu produto. Dentre os atrativos culturais de grande expressão nos destinos, a culinária vem se destacando consideravelmente no setor turístico por ser um produto de grande valor por agrega experiência, além de manter viva a receita/prato, também preserva a identidade local.

A gastronomia enquanto cultura revela a identidade de um lugar através de costumes e tradições no que diz respeito ao modo de preparar os pratos com técnicas próprias e ingredientes específicos da região. Dessa forma, a cultura gastronômica pode ser um importante instrumento de expressão e valorização da identidade de uma comunidade, e aqui na fronteira temos pratos típicos uruguaios implantados no cardápio dos empreendimentos Jaguarenses como o chivito, a pizza a moda uruguaia e a parrillada, sendo que veremos os pratos em destaque:

- Pizza a Moda Uruguaia:

A própria pizza que vem a ser comercializada tem na sua propaganda uma referência particular da fronteira, pois aqui se costuma dizer que a pizza é a moda uruguaia, que se identifica pelo fato de ter o queijo derretido e do sabor inigualável, a pizza é servida na pedra, quadrada, é pedida por metro conforme a foto abaixo: 


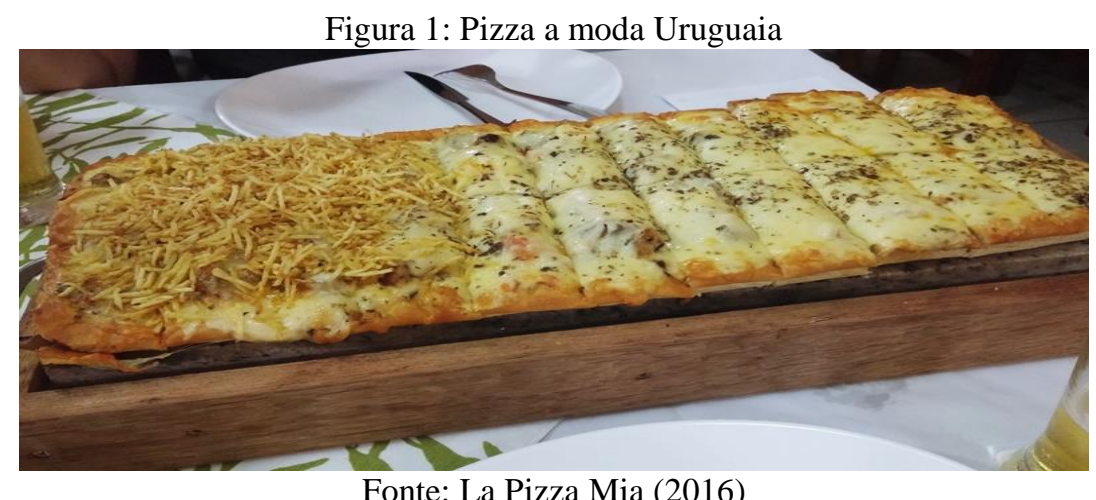

Fonte: La Pizza Mia (2016)

- Chivito:

Um produto muito comercializado na fronteira, inclusive com nome de estabelecimento fazendo menção ao prato. O chivito é composto de um sanduíche de carne e outros ingredientes, geralmente coberto com molho de maionese e servido com batatas fritas, salada russa ou outro acompanhamento, conforme podemos verificar na foto abaixo:

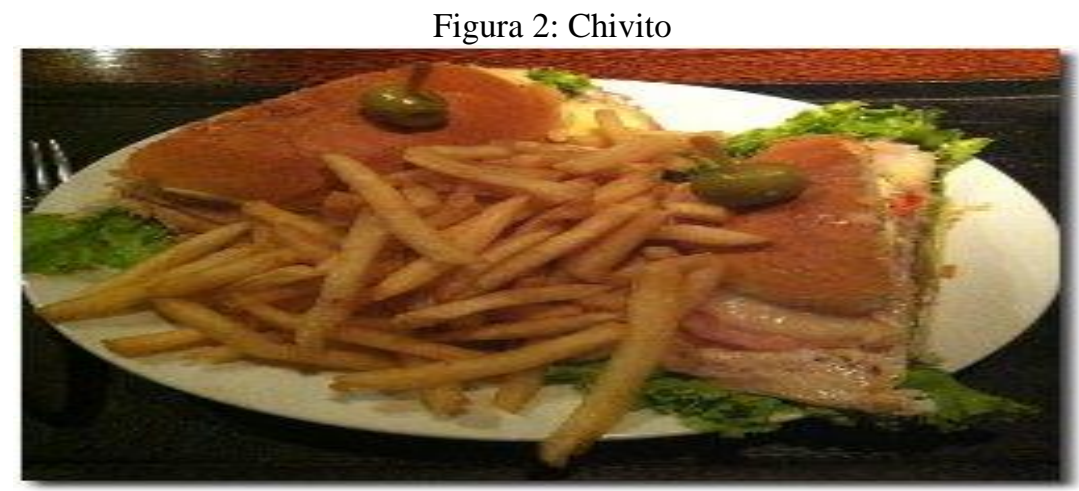

Fonte: Indian foods guide (2016)

- Parrillada:

Prato típico nacional na Argentina e Uruguai, a "parrillada" é um jeito diferente de fazer churrasco. Ao invés de privilegiar as chamadas "carnes nobres", aproveita com muita criatividade e sem nenhum preconceito várias alternativas de sabor e textura do mesmo boi, na qual e colocado e assado sobre uma grelha, na qual podemos ver na foto abaixo: 


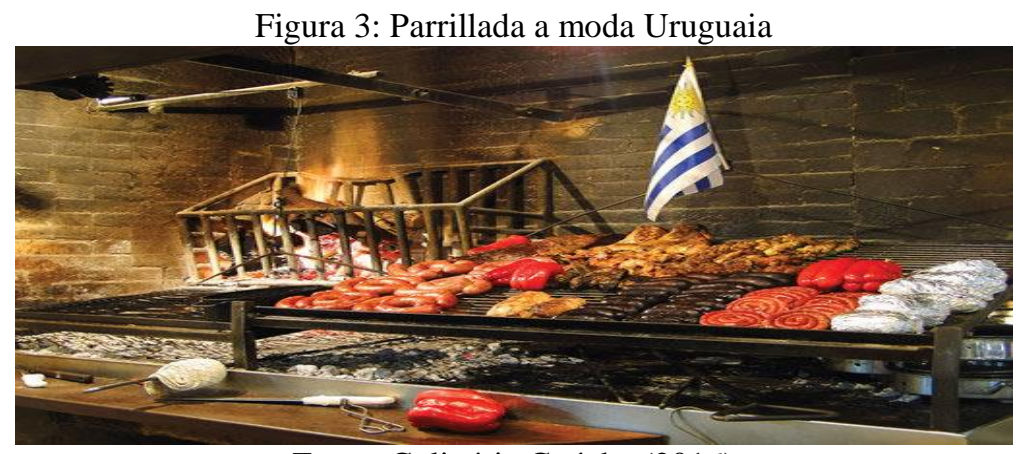

Fonte: Culinária Gaúcha (2016)

Sob a ótica regional é preciso entender o que faz com que se mantenha viva a gastronomia local e a valorização da própria população, o fato da própria comunidade consumir os pratos que são oferecidos, que conhece e prepara os seus alimentos de modo diferenciado e peculiar de uma região para a outra, isso faz com que a fronteira tenha um diferencial relativo ao turismo, por poder oferecer um produto com características exclusivas dos dois países. Pode-se observar que a culinária é bastante peculiar e variadas de uma região para a outra, e devido a forte influência dos povos fronteiriços fazem dos uruguaios e brasileiros que se tem na fronteira, absorvendo a cultura um do outro, baseando que sua formação histórica e a sua extensão territorial sejam propícias a se ter uma imensa opção em variedades de alimentos, na qual devem ser ofertados aos turistas, porém sem perder a particularidade de como são preparados e consumidos e hábitos de um lugar para o outro

Na perspectiva da fronteira, um turista não precisa desejar atravessar a ponte e ir até o Uruguai para vivenciar a sua cultura e comer de seus pratos gastronômicos, pode fazer nos restaurantes aqui da cidade mesmo, por cultivarem a tradição de servirem os pratos tantos da culinária brasileira quanto uruguaia. Um fato importante é que os restaurantes no lado uruguaio não costumam funcionar no período da noite, isso faz com que o turista possa provar a culinária sem ter que perder a viagem, contudo algumas pessoas relatam que fazem a experiência de comer nos restaurantes do lado uruguaio em um período, e depois procuram os estabelecimentos do lado brasileiro, para assim poderem comparar os pratos servidos dos dois lados e terem a real experiência da interação cultural, além de analisar a forma de preparo dos pratos e comparar se utilizam os mesmos ingredientes, observando assim que não perdem suas caraterísticas pelo fato de estarem sendo servidos em países diferentes.

Não é a limitação da fronteira que vai impedir que dois países comercializassem e façam a interação da sua cultura, e no caso das duas cidades é marcante a influência uruguaia 
na gastronomia local, sem deixar de lado as tradições oriundas da cultura gaúcha, sendo que os turistas brasileiros costumam também ir ao lado uruguaio para comprar produtos gastronômicos autênticos de lá, como o alfajor, o doce de leite e o queijo, que no caso dos dois últimos produtos, são produzidos no estado, contudo os uruguaios já conquistaram os brasileiros, sobretudo os fronteiriços, porém o fato dos produtos uruguaios terem criado uma identidade e de ser bem divulgado faz com que o turista tenha a curiosidade de comprar e consumir.

Sabe-se que os turistas que vem a fronteira com o propósito de fazer compras, porém a gastronomia atua apenas como complemento da oferta turística local e, se devidamente planejada e organizada, pode transformar a realidade local, multiplicar os benefícios ocasionados pelo turismo nos destinos e conseguinte nas comunidades.

\section{A importância da gastronomia local como fator de desenvolvimento do turismo}

O turismo e a gastronomia estão diretamente ligados, por isso o turismo gastronômico é uma das formas de preservação do patrimônio imaterial à medida que se apropria da cultura se transformando em produtos para o consumo, ressaltando assim que neste sentido, a gastronomia é uma das manifestações que caracterizam o patrimônio cultural e que conforme Ávila (2009) pode ser utilizada pelo turismo como atrativo turístico, fazendo com que o destino turístico possa ofertar um produto diferenciado em relação à competitividade no mercado turístico.

A gastronomia já se destaca como um atrativo para a população local, porém se necessita trabalhar e fomentar para alcançar o potencial quando se fala em turismo, entretanto, ainda não é caracterizada como produto turístico efetivo, visando que muitos dos turistas que consomem os produtos passam a conhecer somente quando lhe é perguntando se possuem interesse em provar algo diferente, desconhecendo assim o fator de lhe ser ofertado peculiaridades regionais. Os autores Jones e Jenkis (2002) fazem uma abordagem sobre a importância da relação da alimentação e do turismo, as quais procuram identificar qual o fato que fez com que os alimentos passassem a se tornar parte da representação para a promoção da atividade turística, bem como instrumento de valorização cultural local, se tornando um diferencial:

"O conceito de alimentação incorporado ao turismo evoluiu desde suas raízes históricas e mais gerais, associadas à indústria da hospitalidade, até o significado mais amplo de turismo de alimentos- food tourism, a ponto de converter os produtos alimentícios em uma importante ferramenta para a promoção de destinos. Os alimentos são agora utilizados para desenvolver nichos de mercado. Sustentar 
identidades regionais, desenvolver um turismo de qualidade e um turismo sustentável” (JONES e JENKINS, 2002, apud CAMARGO, p.259).

Cada região brasileira possui uma variada e diferenciada culinária, assim como a fronteira Brasil/Uruguai que tem sua identidade própria para a cultura gastronômica, que segundo Chagas (2006) apud Martins e Baptista (2010, p.537), afirma que "um país com as dimensões continentais como o Brasil apresenta significativa diversidade regional, derivada não apenas de seus aspectos físicos, mas também de variadas condições históricas e de apropriação e colonização do território".

A gastronomia conforme Mascarenhas (2010) tem vínculo com a atividade turística tanto por meio da produção dos alimentos, pois as paisagens são elementos significativos para o turismo, como também por meio da transformação do alimento em prato típico ou regional que será apresentado ao visitante. O consumo de um alimento visto sob esta ótica deve considerar o processo desde a aquisição da matéria-prima, o transporte e a estocagem, até a manipulação e transformação em alimentos, ou seja, o preparo e o serviço, pois a percepção do gosto representa uma experiência mista e unitária de sensações olfativas, gustativas e táteis percebidas durante a degustação.

Quanto à gastronomia regional, Cordeiro e Menegazzi (2013) apontam que a gastronomia quando representa a tipicidade da cultura local, é base para impulsionar o desenvolvimento local, sendo gerador de riquezas em uma região, a partir do turismo. Mas ressalta o problema da falta de recursos humanos capacitados para o ramo da hospitalidade, o que pode ser causa para a redefinição da cultura culinária para adequação do desejo do consumidor, porém a identidade cultural reforça a territorialidade exercida e geralmente provoca um sentimento de proteção daquele território em relação aos agentes externos, vistos como certa ameaça à identidade do grupo. Vale a pena então destacar, aqui, a dimensão simbólico-cultural do território, tendo em vista a amplitude que o enfoque territorial abrange.

De acordo com Santos e Ruckertii (2014, p. 1107) observa-se que pelo processo precário de desenvolvimento das regiões de fronteira, visando à falta de investimento, o turismo vem se mostrando como um dos fatores dinamizadores dessas fronteiras, principalmente das fronteiras internacionais. Dessa forma, Cruz (2010) apud Santos e Ruckertii (2014) destaca que:

Turismo de fronteira é viajar entre territórios transfronteiriço, entre países vizinhos por vias do processo de cooperação ocasionando acesso aos atrativos turísticos. Diante disso, a conceituação do turismo de fronteira está ligada a viagem aos territórios transfronteiriço, entre países para poder aproveitar seus diferentes 

e-ISSN 2016/Atual: 2525-7870 | e-ISSN 2015/2016: 2447-018X

potenciais turísticos, quer seja a paisagem natural, aventura, lazer, eventos culturais, gastronomia entre outros tantos. (CRUZ, 2010 apud SANTOS e RUCKERTII, 2014, p. 1107).

Assim, fica claro que para se ter o turismo e o desenvolvimento local em área de fronteira, precisa primeiramente existir um processo de integração entre territórios e sociedade, para se tornar um potencial a fim de se identificar como um novo modelo econômico que surge, funcionando assim como uma das principais atividades para o desenvolvimento da região. (PAIXÃO, 2006).

A falsa ideia de possuir um limite por ser fronteira, tradicionalmente, o imaginário associado às fronteiras, a via como linha de separação; as pessoas entendem como se tivesse um muro que não pode ser ultrapassado, de que a cultura e a interação são limitadas, porém conforme CASTROGIOVANNI e GASTAL (2006,):

A pós-modernidade, ao derrubar muitos paradigmas, trás consigo este novo imaginário para fronteiras, agora como espaço de trocas ou como o "lócus onde se encontram culturas diferentes, sociedades diferentes, economias diferentes, populações diferentes, enfim, onde ocorrem mudanças quantitativas e qualitativas nas vidas das pessoas e populações envolvidas (...)" (CASTROGIOVANNI e GASTAL (2006, p.9)

Nesse mesmo contexto, vem ressaltar a importância da interatividade no turismo, que promove o conhecimento, abrangendo assim a relação amigável, na qual sofre influências sociais, culturais e politicas, na qual reforça JUNIOR (2011):

O turismo, da mesma forma, na medida em que propicia o contato entre distintas culturas, não apenas promove o encontro e o diálogo de identidades, mas cria ambientes de negociações e conflitos sociais, de resistência e confrontos políticos que advêm de condições históricas internas, assim como das contradições colocadas pela situação de contato entre sociedades e culturas diversas. (JUNIOR, 2011, p. 10)

Porém nas cidades gêmeas apresenta uma particularidade incomum referente as barreiras culturais que são muitas vezes impostas, pois há uma interação da sua cultura muito marcante, formando-se assim uma aparência que está tudo ligado, sem nenhuma divisão fronteiriça tornando-se assim num lugar diferente na qual segundo DE ALMEIDA PRADO (2005):

O relacionamento entre as cidades-gêmeas é um cenário real, imperativo e corriqueiro na fronteira. Tanto oficial, como "oficioso", as práticas de cooperação entre a população e os organismos públicos estão presentes. Sejam em práticas que envolvem fatores de segurança e economia, passando pelos aspectos culturais ou até mesmo, políticos. As cidades-gêmeas possuem espaços de relacionamento 
permanentes e em muitas vezes, de características pragmáticas, onde a negociação, a integração e o compartilhamento de infraestrutura e de espaços comuns são constantes. (DE ALMEIDA PRADO. 2005 p.7).

Diante da perspectiva de que as pessoas ainda percebem a fronteira entre Brasil e Uruguai apenas como local só para se fazer compras, podemos ver que vai além, sendo que é fundamental perceber que a gastronomia é um dos fatores que pode ser facilmente identificado no contexto da interação entre os dois países, pois na região é parte integrante da cultura local, sendo também uma estratégia para integrar o turismo e a gastronomia por forma a promover o desenvolvimento económico, na medida em que o Turismo Cultural passa a ser incentivado em várias localidades e a gastronomia torna-se um importante ponto de contato do turista com a localidade visitada, bem como com uma série de conteúdos e tradições.

Se uma região com potencial turístico gastronômico souber promovê-lo, torna-se mais atrativa tanto para o turista que viaja por outros motivos como no caso mais especifico da fronteira, a questão de compras, ampliando os ganhos da região com sua visitação, além de promover o desenvolvimento sustentável de ambos os lados.

\section{Considerações Finais}

Com relação à qualidade dos destinos turísticos, considera-se que este é fator fundamental no contexto atual visando à alta competitividade dos mercados turísticos, necessitando estar preparados tanto na estrutura de atendimento como na diversificação de produtos qualificados para atender as novas exigências e garantir a imagem do destino turístico. Sendo assim, a qualificação nos serviços de alimentação do município de Jaguarão pode se torna forte como atrativo turístico sendo valorizado como elemento de qualidade e competitividade entre destinos turísticos e como elemento gerador de desenvolvimento regional.

A gastronomia típica deve ser valorizada, principalmente, sob a ótica do turismo no sentido de proporcionar ao visitante uma oportunidade de contato não apenas na questão do sacio da fome como também no sentido figurado de degustar as tradições locais, ritos e valores alimentares e permite aos autóctones a ideia de pertencimento do lugar, uma vez que seus valores, saberes, fazeres estão sendo valorizados.

Vale ressaltar que é fácil perceber que a gastronomia é parte integrante da cultura fronteiriça, sendo assim, pode se moldar como atrativo turístico sendo valorizada como elemento de qualidade e competitividade e como elemento gerador de desenvolvimento regional. Certamente, os empreendimentos gastronômicos de Jaguarão tem potencial para 
fomentar o turismo gastronômico na fronteira, porém para que a gastronomia seja consagrada como atrativo ou produto turístico, é necessário que haja uma mobilização para que esse segmento seja inserido no plano de desenvolvimento turístico do município e da região.

Os eventos gastronômicos acontecem com o uso de determinado produto ou ingrediente específico, assim como há eventos que giram em torno de um único prato que retrata a tradicionalidade da cultura local. Embora possa realizar festivais gastronômicos com produtos não específicos de determinada região em que o evento está inserido, são os festivais com bebidas, gêneros alimentícios e pratos tradicionais que mais chamam à atenção dos turistas quando realizados em seus locais de origem. É importante destacar que a cidade poderia promover eventos relacionados à temática, fazendo assim com que os turistas que visitam a localidade possam experimentar no mesmo dia, uma variedade culinária diferenciada.

\section{Referências}

ÁVILA, M.A. (org.) Política e planejamento em cultura e turismo. Ilhéus: Editora da UESC, 2009.

CASTROGIOVANNI, Antonio Carlos; GASTAL, Susana. Fronteira e Turismo: Tensionando Conceitos. IV SEMINTUR-Seminário de Pesquisa em Turismo do MERCOSUL. III Seminário da Associação Nacional de Pesquisa e Pós-Graduação em Turismo. Caxias do Sul/RS, v. 7.

CHAGAS, C., 2006, Estilo Brasileiro de Comer, Dia Mundial da AlimentaçãoAgricultura e Diálogo Intercultural. In: MARTINS, Uiara e BAPTISTA, Maria Manuel. A Gastronomia Portuguesa no Brasil - um Roteiro de Turismo Cultural. RT\&D, 2010.

CLICRBS. Carnaval de rua faz população dobrar em Jaguarão. Disponível em: <http://gaucha.clicrbs.com.br/rs/noticia-aberta/carnaval-de-rua-faz-populacao-dobraremjaguarao-128856.html> Acesso em 25 jul. 2016

CORDEIRO, W. C; MENEGAZZI, F. D. Contribuição da gastronomia local ao enoturismo: um estudo do vale dos vinhedos- RS. 2013.

DE ALMEIDA PRADO, Henrique Sartori. Lojas Francas, a fronteira e as perspectivas para as cidades-gemeas brasileiras duty free shop. In: Seminario America Platina. 2005.

IBGE. Instituto Brasileiro de Geografia e Estatística. Perfil regional. Disponível em: <www.ibge.org.br.> Acesso em: 15 jul. 2016

INDIAN FOODS GUIDE . Chivito - Sandwich Style Dish from Uruguay. Dísponivel em: $<$ http://www.indianfoodsguide.com/food-articles/global-cuisine/chivito-sandwich-style-dishfrom-uruguay-.html> acesso em 15 jul. 2016 
RELACult - Revista Latino-Americana de Estudos em Cultura e Sociedade

JONES, Andrews. y JENKINS, Ian; (2002), “A taste of Wales - Blas Ar Gymru"”:

institutional malaise in promoting Welsh food tourism products. En HJALAGER, Anne-

Mette. y Richards, Greg. (editors), Tourism and Gastronomy. London, Routlede

JÚNIOR, Álvaro Banducci. Turismo e fronteira: integração cultural e tensões identitárias na divisa do Brasil com o Paraguai. Pasos: Revista de turismo y patrimônio cultural, v. 9, n. 3, p. 7-18, 2011.

LA PIZZA MIA. Sabores de Pizzas. Disponível em <www.lapizzamia.com.br> acesso em 15 jul. 2016.

PAIXÃO, Roberto Ortiz. Turismo regional: problemas e perspectivas. In: IV SIMPÓSIO SOBRE RECURSOS NATURAIS E SÓCIOECONÔMICOS DO PANTANAL. Corumbá/MS, 23 a 26 de novembro de 2004.

PAIXÃO, Roberto Ortiz. Globalização, turismo de fronteira, identidade e planejamento da região internacional de Corumbá/MS. 2005. Tese de Doutorado. Universidade de São Paulo.

MARTINS,Uiara; BAPTISTA, Maria Manuel. A Gastronomia Portuguesa no Brasil- um Roteiro de Turismo Cultural. In: RT\& D, nº 13, 2010.

SANTOS, Christiano Ricardo dos; RÜCKERTII, Aldomar Arnaldo. Turismo, fronteira e territorio: uma análise do território transfronteiriço missioneiro. Anais do I Congresso Brasileiro de Geografia Política, Geopolítica e Gestão do Território. Rio de Janeiro: Editora REBRAGEO, 2014.

SABERES DO SUL. 10 pratos típicos da culinária gaúcha. Disponível em <http://revistasaboresdosul.com.br/top-list-a-tradicional-culinaria-gaucha/> acesso em $17 \mathrm{de}$ agosto de 2016.

VEAL, A. J. Metodologia de pesquisa em lazer e turismo / A. J. Veal ; tradução Gleice Guerra, Mariana Aldrigui. - São Paulo : Aleph, 2011. 